\title{
Implementation of Measurable and Sustainable Actions to Improve Employee's Engagement and Business Performance: Global Medical Clinical \& Regulatory Affairs (GMCRA) - A Role Model at Fresenius Kabi
}

\author{
Silke Baasner
}

\begin{abstract}
The department Global Medical, Clinical \& Regulatory Affairs (GMCRA) was founded in 2010 and is Fresenius Kabi's driving force and strategic unit for medical, scientific and regulatory affairs. This unit provides global standards to ensure the safety of products and patients. Since its foundation, the team as well as its tasks and responsibilities are continuously growing and the department has a clear understanding of how to develop further. The basis for this development process is an ambitious strategy, excellent operations and a strong high performance culture. To bring a high performance culture to life and to add value to the company the management of GMCRA has started the initiative Excellence@GMCRA. To evaluate the status regarding employee engagement a computer assisted web questionnaire on feedback culture at GMCRA, focusing on leadership behavior and staff development, was performed. In the following article the results are described as well as the actions the management decided to implement, namely:
\end{abstract}

- Onboarding program for new employees with a buddy concept

- Regular 1:1 meetings with superiors and employees

- Individual personal development plan (PDP) for each employee

At the end of the chapter a conclusion is drawn if the overall goal to increase job performance of employees within GMCRA has been reached and if this has a positive effect on business performance.

\footnotetext{
S. Baasner $(\bowtie)$

Fresenius Kabi Deutschland GmbH, Bad Homburg, Germany

e-mail: silke.baasner@fresenius-kabi.com 


\section{Background}

GMCRA is a globally acting department within the Pharmaceuticals Division of Fresenius Kabi. In the year 2014, the initiative Excellence@GMCRA was kicked off to shape the future of the department as well as to foster business performance. To observe the status quo regarding the satisfaction of employees and to figure out, which processes can be improved within GMCRA a first Employee Online Survey regarding "Feedback Culture at GMCRA" was performed. With every one of the 75 GMCRA employees participating in the survey, the commitment was extraordinarily high. The survey was performed as a computer assisted web interview, which was self-completed by the participants, managed and hosted by an independent international research company. All responses were handled strictly anonymously. In the present article, the first part of the survey with six questions dealing with the leadership behavior and staff development will be analyzed and discussed. The summary of results is depicted in Table 1.

In a nutshell, the results of the survey as well as the outcome of group work from a GMCRA Excellence Conference demonstrated that no strong feedback culture is established in the organization (only $64 \%$ agree on getting sufficient feedback from their superior) and many colleagues $(\sim 62 \%)$ felt a lack of personal development options and wanted more transparency about career progression. Additionally, GMCRA lacked a common guideline on the onboarding process of new employees. As a consequence, new team members often felt not being welcomed enough and had not developed a team spirit. Furthermore, tasks and competences were not communicated appropriately within the organization and team members felt hesitant to contact colleagues from other groups within GMCRA.

For the preparation of concepts to establish a sustainable feedback culture at GMCRA as regular part of the day-to-day work from the beginning, several working groups were formed. They consisted of team members from different management levels and met regularly during the course of the last years. This effort should enable

Table 1 Summary of results of employee online survey

\begin{tabular}{l|l|l|c}
\hline Question & $\begin{array}{l}\text { Agree } \\
{[\%]}\end{array}$ & $\begin{array}{l}\text { Indifferent } \\
{[\%]}\end{array}$ & $\begin{array}{l}\text { Disagree } \\
{[\%]}\end{array}$ \\
\hline I get sufficient feedback from my direct superior? & 64.0 & 32.0 & 4.0 \\
\hline $\begin{array}{l}\text { I can understand and follow the feedback I receive from } \\
\text { my direct superior? }\end{array}$ & 82.7 & 16.0 & 1.3 \\
\hline $\begin{array}{l}\text { I feel valued by my direct superior? } \\
\begin{array}{l}\text { The work expectations of my direct superior are clear, } \\
\text { understandable and comprehensible? }\end{array}\end{array}$ & 72.0 & 26.7 & 1.3 \\
\hline $\begin{array}{l}\text { I can have a constructive and critical dialogue with my } \\
\text { direct superior? }\end{array}$ & 80.0 & 16.0 & 4.0 \\
\hline $\begin{array}{l}\text { My direct superior points out specific strengths and } \\
\text { development opportunities to me in regular employee } \\
\text { feedback sessions? }\end{array}$ & 37.3 & 41.3 & 21.3 \\
\hline
\end{tabular}

Own representation based on the survey results 
all team members working together much closer and to become even more effective. Furthermore, an atmosphere should be generated allowing that everybody can fearlessly and candidly address feedback, independently from hierarchies and departments. After alignment with the management team, the respective working groups suggested the following actions to be implemented at GMCRA:

- Onboarding program for new employees with a buddy concept

- Regular 1:1 meetings with superiors and employees

- Individual personal development plan (PDP) for each employee

\section{Statement of Expectations}

\subsection{With Onboarding the Bond of Employees to the Company will be Increased}

To generate a welcome atmosphere and to increase the team spirit from the beginning an onboarding program with a buddy concept was developed in close collaboration with colleagues from the Talent Management department of Corporate Human Resources (CHR) at Fresenius SE. The concept for onboarding at GMCRA is a systematic process with a personal touch and shall ensure a fast adaptation and identification of new employees with the department. The elaborated process proposal was introduced to all team members on a GMCRA Excellence Conference. After approval by the local works council of Fresenius according to German law (Betriebsverfassungsgesetz), it was set in force in July 2018. One important part of the program is the onboarding plan where different topics are covered: e.g. administrative aspects (work place and IT systems), social aspects (networking systems, teambuilding events and company related sport activities), professional aspects (trainings, webinars and mentoring program), cultural and legal aspects.

The onboarding is divided in different phases: before day 1 , day 1 , week 1 , month 1-3 and month 4-6 and is completed after 6 months. During these phases several feedback sessions are recommended. Each new employee is supported by a buddy who is defined as a fellow employee providing advice and guidance. In general, the onboarding process should help to settle an outsider down to the workplace and to the respective company culture.

\subsection{Regular Feedback Meetings with Superiors will Engage Employees}

As a first step on the way to implement a strong feedback culture within GMCRA and true to the motto 'Leadership is a language game' (Van Quaquebeke and Felps 2018) a seminar was designed. The Constructive Feedback \& Criticism Workshop 
was conducted for all team members. In the theoretical introduction of the workshop definitions of feedback and criticism were given and the purpose and importance of feedback for individuals and organizations and the qualities of constructive feedback were explained. In the practical part exercises on giving and receiving of feedback were performed and ways to facilitate discussions were trained. Additionally, a proposal for the feedback practice in GMCRA including a guideline on expressing criticism clearly and constructive was worked out.

\subsection{Personal Development Plans will Lead to Better Performance}

The last expectation that PDPs will lead to better performance is due to my personal experiences. Since I have started my work in the department GMCRA 8 years ago, I have implemented PDPs for each member of my team. The preparation of the development plan is carried out on a voluntary basis and the level of maturity was individualized. After a management assessment and accompanied by colleagues from the Talent Management department of CHR at Fresenius SE training measures for professional knowledge as well as for soft skill development are discussed and agreed on with the respective employee. All activities are collected in a personal document and are constantly adapted to individual needs. Thereby, the personal development planning is a cyclical process according to the Chartered Management Institute (CMI) and consisting of seven steps (Managers.org.uk 2013). After defining the purpose for development of the employee the needs are defined and appropriate training or development opportunities are selected. The action plan is generated and the agreed actions are conducted. At the end of the cycle the outcome is evaluated and further directions are defined. The steps have to be adapted to changed goals or needs after each cycle round. This process needs a close collaboration and regular feedback between superior and employee leading to a deep relationship. In my point of view, this continuous caring is associated with an increase of engagement and therefore a better performance.

\section{Managerial Implications}

To improve performance and sustainability within an organization, mechanisms to track progress for meeting goals and executing strategies need to be transparent. Organizations, especially in the health care sector, have a responsibility to follow current market trends of lowering cost and simultaneously improving quality and patient satisfaction. Therefore, balance in managing the needs of various customers as for example patients, health care providers and insurance companies are important. Strategic goals can be monitored using a Balanced Score Card as a strategic 
management tool as described in the publication of Kaplan and Norton (Kaplan and Norton 2007). As well as the classical financial and operational measures the management of employees has to be taken into account. A new area of "people management" has started and employees are defined as "human capital". Recently, Ram Charan and co-authors published the book Talent Wins-The New Playbookfor Putting People First (Charan et al. 2018). In particular, the book was written for top managers and leaders with the goal for teaching them, who and not what the key to the future of their company is. Each of the three authors is quite experienced in consulting board members of large, globally acting organizations and assisting them by generating value and becoming most competitive. They wrote this book after having recognized the tremendous shift in the importance of what is really driving the value of companies' success, namely the talent management. By using real world examples and sharing best practice approaches from companies like Amgen, General Electric and PepsiCo they draw a clear picture, how to reshape human resources tasks and responsibilities and to create a talent-driven organization (Charan et al. 2018).

The press release regarding the Gallup Engagement Index 2016 clearly accentuates the above mentioned facts. In this article the business numbers for Germany were published proving that the engagement of employees is directly connected to the performance of an organization. In the headline of the respective press release, the authors pointed out that 'Schlechte Chefs kosten deutsche Volkswirtschaft bis zu 105 Milliarden Euro jährlich' (Translation: Bad bosses cost the German economy up to 105 billion Euros per year). The results of the Engagement Index clearly showed that only $15 \%$ of employees in Germany are engaged, whereas $85 \%$ are not engaged or actively disengaged at work (Nink 2017). Most of the employees in Germany have no emotional bonding to their company resulting in competitiveness factors as rate of absence, reduced productivity and quality and customer loyalty. Additionally, this is associated with high turnover, and every third employee in Germany is looking for a new job. There is a large gap between wishes of employees and the reality regarding leadership skills of supervisors. Only $21 \%$ of employees are happy with and motivated by the behavior of their superior. The lack of feedback is a main issue for the employees dealing with their respective leaders in the day-to-day business. Only $14 \%$ of employees report a continuing feedback process over the year, and only $38 \%$ feel that the feedback they receive from the superior is helpful to improve their work outcome (Nink 2017).

A comparable percentage distribution of engaged versus not or disengaged employees worldwide is reported by Jim Harter (2017) in his recent State of the Global Workplace report. In this report, data from employees in 155 countries were assessed regarding the effectiveness of organizations fostering employee's engagement. Worldwide the proportion of full-employed adults, who are enthusiastic and highly engaged about their work and workplace, is only $15 \%$. According to Harter, this low number of engaged people limits organizations in the creation of a high performance culture. Companies with high engaged employees are $17 \%$ more productive and $21 \%$ more profitable in comparison to companies with a high number of disengaged people. The research of Harter and colleagues clearly shows that 
engagement as well as performance can be fostered by the fulfillment of basic human needs (J. Harter 2017).

In my point of view, these numbers are alarming because they are on the same high level for more than a decade.

But luckily, the recently published survey results of the Chartered Institute of Personnel and Development (CIPD) showed the increasing awareness of organizations to invest in people or talent management activities, which is seen as a competition factor. Therefore, 54\% of CEOs in the UK participating in the survey stated that talent management has a very high priority and the budget for employee development has increased (CIPD.com 2017).

For an organization it is highly important to optimize profitability as well as to balance short-time and long-time goals within the business model to guarantee sustainable success. This follows a very simple rule: For sustainable financial growth, customers have to keep being satisfied and therefore, products or services have to add value to the customers. To achieve the highest level of satisfaction for the customer, companies have to deliver excellent products. This is closely related to engaged people working within the companies. To assess how effective organizations are delivering products and services and on what level of excellence they are working, a holistic approach is needed. The European Foundation for Quality Management (EFQM) Excellence Model provides a framework that encourages the cooperation, collaboration and innovation and helps organizations to increase their effectiveness (EFQM.org 2017).

A practical application of the EFQM Excellence Model is described in the article of Miriam Garbarova (Garbarova 2017). According to Garbarova, every organization needs success and is trying to be successful. Thereby, the employee is a key factor to generate success. In her article Garbarova describes the EFQM Excellence Model as a beneficial tool for the improvement of human resources management. She concluded that the use of the EFQM Excellence Model can lead to increase companies' ability to compete and to satisfy their employees.

\subsection{Implications on Fresenius Kabi}

What can we, as managers, learn from these very positive examples? Beside the above described high impact of "people management" and the importance of "human capital" organizations like Fresenius Kabi have to meet requirements from several authorities, e.g. European Medicines Agency (EMA), U.S. Food \& Drug Administration (FDA), Federal Institute for Drugs and Medical Devices (BfArM). Therefore, employees of healthcare companies have to follow strong rules and regulations. By the implementation of standards which are merged in a Quality Management System (QMS), the control of compliance is simplified. Typical standards for a QMS are published by the International Organization for Standardization (ISO), e.g. ISO 9001 (iso.org). 
From my point of view, it is strongly recommended to follow the example of other organizations like Robert Bosch GmbH Blaichach Plant, one of the three Global EFQM Excellence Award winners in 2017 (EFQM.org 2017), and to extend the QMS of Fresenius Kabi with aspects of the EQFM Excellence Model. Interestingly, Vamed $K M B$, a company belonging to Fresenius $S E$ group and being in charge for the technical operation of the Vienna General Hospital was the EFQM Excellence Award Prize Winner 2015 in the category "adding value to customer". Vamed $K M B$ is using the EFQM Excellence Model since 2003 and was awarded three times from 2010 to 2013 in different categories (Vamed.com).

Zinta S. Byrne (2014) proposed a very simplified model in her book about the understanding of employee engagement. According to this model, job engagement is based on three parts: The personal environment, the work environment and the person itself. In relation to the time the interaction of these three parts prognosed how engaged an individual will be. Thereby, the Personal Environment is defined as external regarding to the job (e.g. family, friends, house, health); the Work Environment defined as internal (e.g. organizational culture, leadership, internal resources, support and stability) and the Person itself (e.g. personality, identification and focus). The model consists of various cycles showing that the process of engagement is self-sustaining and engagement itself can stimulate more engagement over time.

As to my judgment, this model fits very well to the topic discussed within this chapter, and I tried to adapt the model accordingly in Fig. 1. The managerial actions, which will be implemented at GMCRA, are related to the work environment at GMCRA. An engaged team member, who has chosen to use these actions for further development will be motivated internally resulting in more engagement.

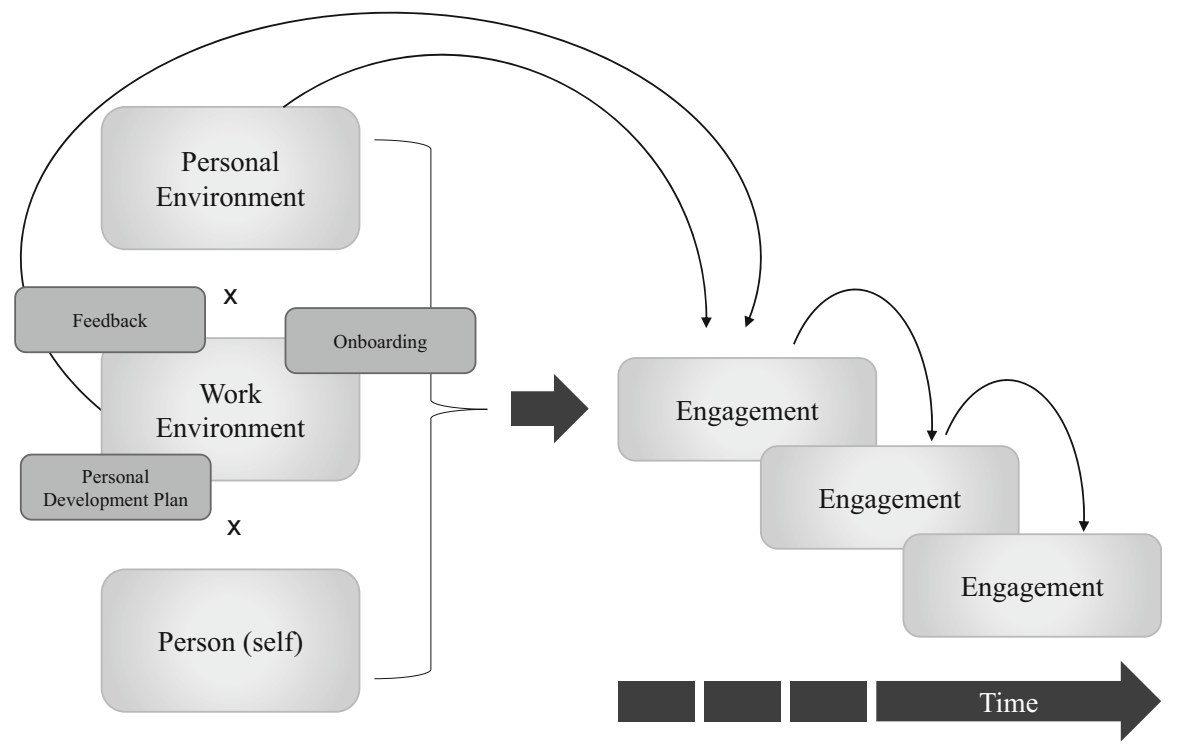

Fig. 1 Proposed model of employee engagement. Own interpretation based on Byrne $(2014,199)$ 
The actions to increase employee's engagement, which can be fitted into this model, included but are not limited to onboarding, regular 1:1 meetings and PDP. Other measures are currently discussed within GMCRA, e.g. job rotation, mentoring program, flexible working times, international exchange program or attractive working space. The most advanced activity is the mentoring program, which is planned since 2 years and will be rolled out at Fresenius Kabi and Fresenius SE soon. With the help of mentors, ambitious employees can increase their self-reflection about opportunities and development possibilities at Fresenius Kabi based on the experiences of the mentors.

\section{Direction for Future Research}

The most obvious future research is to perform the second Employee Online Survey at GMCRA. This is recommended not earlier than 1 year after implementation of the described managerial actions. For further research, a larger group of Fresenius Kabi employees should be included in the survey, or the circle of participants should be spread out to appropriate departments within the Pharmaceuticals Division with approximately 5000 employees. In the meantime, the monitoring and evaluation framework of the initiative Excellence@GMCRA should be developed. The use of a planning tool, e.g. a Planning Triangle, could help to clarify what should be achieved and on the basis of the Planning Triangle a list of outputs and the respective output parameters can be defined. The outputs should be prioritized; measures set realistically and number of output indicators limited. Thereby, the planning of how to measure "soft" outcomes (e.g. engagement of employees) has to be done very carefully. Because the change of how people think or feel is impossible to assess directly, it could be useful to measure observable behavior changes. Therefore, appears to be helpful to set more targeted indicators such as participant's reactions to and satisfaction with training programs or employees changes in knowledge, skills and attitudes and lastly there modified on-the-job behavior. During the course of the research, the regular review and the adaptation of the prioritization of outcome indicators is needed. Survey questions, topics for focus groups and interview schedules can be defined according to the outcome indicators. In this context the publications by Stockmann (2006) as well as the consultancy of the Center for Evaluation (CEVAL) could be helpful (Stockmann 2006).

\section{Conclusion}

The purpose of this article was to describe the implementation of managerial actions like onboarding, regular 1:1 meetings and individual PDPs to improve employee's engagement and business performance at GMCRA. Furthermore, an attempt has 
been made to figure out how the effects of the described actions can be measured and sustainability ensured.

In summary, the stated expectations could be verified by using literature data and first impressions of GMCRA employees as well as by setting the context in relationship to other organizations. By describing the combination of a QMS with an excellence model and by applying this to the circumstances at Fresenius Kabi, recommendations for managers were derived. Furthermore, a proposal for a model of employee engagement was adapted to the managerial actions implemented at Fresenius Kabi.

A take home message of this article is that "human capital" is of highest importance, and in times of shortage of skilled professionals, bonding of employees to their organization is a key performance factor.

Numerous studies and surveys performed by well-known researchers and management consultancies, e.g. Gallup, McKinsey or Deloitte, have shown that the emotional bonding of employees to their company is dramatically bad (Harter et al. 2016) and $85 \%$ of employees are not engaged with their work and workplace (Nink 2017). As a consequence thereof, it was predicted that $66 \%$ of the Millennials (Generation Y, born between early 1980 and early 2000) will leave their company by the year 2020 (Deloitte.com 2016).

Gary Hamel, one of the most famous American management experts, advised to change the most common way of thinking of leaders, who believe that the needs of the organization have to be put in front or on top of the individual needs. In this regard, the needs from an individual employee have to be put first, followed by the institutional needs. In an environment with less hierarchy and more autonomy, talents are able to grow and will be committed to high performance. Instead of being depleted and exhausted because of overloading activities like doing email communication, attending in unproductive meetings and preparing redundant presentations, good leaders should be a role model, should lead by example, should be transparent and thereby, should build trust (Hamel 2012).

GMCRA has started to put people first and to establish a convincing feedback culture. It can be expected that the first implemented actions will lead to increased engagement of employees and to an improved performance culture of GMCRA. With a continuing evaluation process, as described, and a regular adaptation on business needs, sustainability and long lasting success will be ensured. To get support on this journey, a membership in the non-profit organization EFQM is recommended. By combining the EFQM Excellence Model with the existing ISO 9001-2015 standards at Fresenius Kabi, a high performance culture can be built up and competitiveness can be increased.

Currently, several departments within Fresenius Kabi are acting as a role model, and different actions regarding "people management" are established within the organization. Hopefully, these jigsaw pieces will be merged and a commitment for putting people first will be achieved in the whole organization in the near future. According to literature and following the experiences of large, global companies, e.g. Bosch Group, the business success will also be reflected in financial KPIs after a certain time. 


\section{References}

Byrne, Z. S. (2014). Understanding employee engagement: Theory, research, and practice. Abingdon: Routledge.

Charan, R., Barton, D., \& Carey, D. (2018). Talent wins: The new playbook for putting people first. Brighton: Harvard Business School Press.

CIPD.com. (2017). Resourcing and talent planning survey 2017. Retrieved from http://www.cipd. com

Deloitte.com. (2016). The 2016 Deloitte Millennial Survey: Winning over the next generation of leaders. Retrieved from https:/www2.deloitte.com

EFQM.org. (2017). EFQM Global Excellence Award 2017 - Recognition book. Retrieved from http://www.efqm.org/

Garbarova, M. (2017). Improving human resources management using the EFQM excellence model. International Journal of Organizational Leadership, 6(3), 335-340.

Hamel, G. (2012). What matters now: How to win in a world of relentless change, ferocious competition, and unstoppable innovation. Hoboken, NJ: John Wiley \& Sons.

Harter, J. (2017). State of the global workplace.

Harter, J. K., Schmidt, F. L., Agrawal, S., Plowman, S. K., \& Blue, A. (2016). The relationship between engagement at work and organizational outcomes. Washington: Gallup Poll Consulting University Press.

iso.org. iso-9001-quality-management. Retrieved from https://www.iso.org/iso-9001-quality-man agement.html

Kaplan, R. S., \& Norton, D. P. (2007). Using the balanced scorecard as a strategic management system. Harvard Business Review, 74(1), 75-85.

Managers.org.uk. (2013). Personal development planning checklist. Retrieved from https://www. managers.org.uk

Nink, M. (2017). Engagement Index Deutschland 2016 [Press release]

Stockmann, R. (2006). Evaluation und Qualitätsentwicklung: eine Grundlage für wirkungsorientiertes Qualitätsmanagement. Münster: Waxmann Verlag.

Vamed.com. Excellent performance of VAMED KMB. Retrieved from https://www.vamed.com

Van Quaquebeke, N., \& Felps, W. (2018). Respectful inquiry: A Motivational account of leading through asking questions and listening. Academy of Management Review, 43(1), 5-27.

Open Access This chapter is licensed under the terms of the Creative Commons Attribution 4.0 International License (http://creativecommons.org/licenses/by/4.0/), which permits use, sharing, adaptation, distribution and reproduction in any medium or format, as long as you give appropriate credit to the original author(s) and the source, provide a link to the Creative Commons licence and indicate if changes were made.

The images or other third party material in this chapter are included in the chapter's Creative Commons licence, unless indicated otherwise in a credit line to the material. If material is not included in the chapter's Creative Commons licence and your intended use is not permitted by statutory regulation or exceeds the permitted use, you will need to obtain permission directly from the copyright holder.

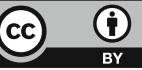

